\title{
PENERAPAN FUNGSI PERENCANAAN SUMBER DAYA MANUSIA DALAM PENDIDIKAN
}

Oleh: Desy Aniqotsunainy

Dosen STAIMS Yogyakarta

\begin{abstract}
Existence of teachers tend to experience a dynamic change, the profile of the ideal teacher is a person who devoted by vocation, a call of conscience, and able to adapt to the times. Human Resource planning for it here as a guide to assist agencies / institutions to be able to think and directing issues demanding change and provides the opportunity to manage change effectively.
\end{abstract}

\section{Abstrak}

Eksistensi guru cenderung mengalami perubahan yang dinamis, profil guru yang ideal adalah sosok yang mengabdikan diri berdasarkan panggilan jiwa, panggilan hati nurani, sekaligus mampu beradaptasi dengan perkembangan zaman. Untuk itu perencanaan SDM di sini sebagai penuntun untuk membantu instansi/lembaga pendidikan agar mampu memikirkan dan mengarahkan masalah-masalah yang menuntut perubahan dan memberikan kesempatan untuk mengatur perubahan tersebut secara efektif.

\section{A. Pendahuluan}

Ada pepatah " ing ngarso sung tulada, ing madya mangun karsa, tut wuri handayani", yang berarti kedudukan guru memiliki makna yang terhormat dalam kehidupan masyarakat, yakni didepan memberi suri tauladan, di tengah-tengah membangun, dan di belakang memberikan dorongan dan motivasi. ${ }^{49}$ Pepatah tersebut menggambarkan kedudukan guru itu senantiasa relevan dengan zaman dan sampai kapanpun diperlukan. Eksistensi guru

49 Isjoni, Guru Sebagai Motivator Perubahan, (Yogyakarta: Pustaka Pelajar, 2009), hlm.10 


\section{Desy Aniqotsunainy : Penerapan Fungsi Perencanaan SDM}

cenderung mengalami perubahan yang dinamis, profil guru yang ideal adalah sosok yang mengabdikan diri berdasarkan panggilan jiwa, panggilan hati nurani, sekaligus mampu beradaptasi dengan perkembangan zaman yang semakin menuntut akurasi para guru melaksanakan fungsinya, semakin tercipta dan terbinanya kesiapan dan keandalan seorang guru sebagai manusia pembangunan.

Guru dalam pendidikan berkontribusi untuk meningkatkan sumber daya manusia (SDM), selain buku yang berkualitas dan sarana gedung. ${ }^{50}$ Kualitas sumber daya manusia(guru) di dalam penyelenggaraan pendidikan merupakan "roh" dari sekolah. Soft property ini menggerakkan sistem kurikulum serta sarana dan prasarana lainnya (hard property) sehingga layanan pendidikan dapat terselenggara. Tidak salah kiranya bahwa salah satu komponen pendukung bagi keberhasilan manajemen peningkatan mutu berbasis sekolah adalah profesionalisme guru.

Menghadapi tuntutan perubahan yang serba cepat akibat kompetisi global dan kemajuan teknologi, para pemimpin sekolah harus mampu mengelola sumber daya manusia dengan fokus pada masalah-masalah yang benar-benar penting, maka perlunya meletakkan SDM sebagai suatu bagian dari perencanaan strategik. Tidak sedikit ayat Al-Qur'an mengisyaratkan untuk selektif dalam memilih orang (SDM), karena memang manusia diciptakan sesuai dengan kadar kemampuannya sendiri-sendiri. Allah berfirman dalam surah Al-Isra [17]: $84: 51$

50 E. Mulyasa, Menjadi Guru Profesional Menciptakan Pembelajaran Kreatif dan Menyenangkan (Bandung: Remaja Rosdakarya, 2007), hlm. 3

51 Departemen Agama RI, Al-Qur'an Tajwid dan Terjemah, (Bandung: CV Penerbit Diponegoro,2010), hlm 290 


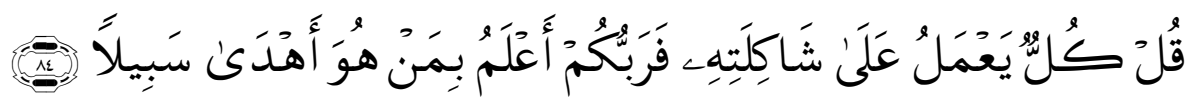

Artinya : Katakanlah: "Tiap-tiap orang berbuat menurut keadaannya masing-masing". Maka Tuhanmu lebih mengetahui siapa yang lebih benar jalanNya.

Allah SWT memerintahkan agar Nabi Muhammad SAW menyampaikan kepada umatnya bahwa tiap-tiap orang itu bekerja menurut kemauannya sendiri-sendiri. Ada orang yang suka bersyukur kepada Allah setiap ia memperoleh nikmat daripadaNya, dan ada pula orang yang mengingkari nikmat yang telah diberikan Allah kepadanya; semuanya bekerja menurut tabiat, watak dan kecerdasan mereka masing-masing.

Dengan demikian, SDM dalam pendidikan merupakan faktor kunci bagi jalannya instansi/lembaga pendidikan pada masa kini maupun pengembangan masa depan. Perubahan yang begitu cepat membuat perencanaan strategi menjadi penting, bahkan perencanaan sering bermanfaat sebagai alat untuk memancing pemikiran dan diskusi daripada sebagai proses untuk mendefinisikan tujuan-tujuan jangka panjang dan rangkaian kegiatan. Untuk itu perencanaan SDM di sini sebagai penuntun untuk membantu instansi/lembaga pendidikan agar mampu memikirkan dan mengarahkan masalah-masalah yang menuntut perubahan dan memberikan kesempatan untuk mengatur perubahan tersebut secara efektif.

\section{B. Perencanaan SDM}

Perencanaan SDM adalah menentukan kualifikasi SDM, yang dibutuhkan instansi baik dalam jangka pendek, menengah dan jangka panjang termasuk jumlah SDM yang dibutuhkan untuk 


\section{Desy Aniqotsunainy : Penerapan Fungsi Perencanaan SDM}

tercapainya tujuan perusahaan. ${ }^{52}$ Perencanaan yang dimaksud bertujuan untuk mempertahankan dan meningkatkan kemampuan organisasi dalam mencapai tujuan/sasarannya, melalui strategi pengembangan/kontribusi pekerjanya di masa depan

Pengertian perencanaan menurut Husaini Usman adalahproses pengambilan keputusan atas sejumlah alternatif (pilihan) mengenai sasaran dan cara-cara yang akan dilaksanakan di masa yang akan datang guna mencapai tujuan yang dikehendaki serta pemantauan dan penilaian dan penilaian atas hasil pelaksanaannya, yang dilakukan sistematis dan berkesinambungan. Proses ini terdiri dari tiga kegiatan yang berurutan yaitu :53

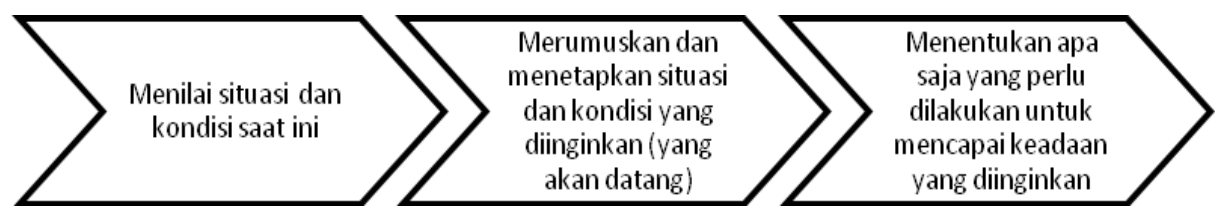

Gambar 1. Proses Kegiatan Perencanaan

Penjelasan di atas mengacu pada makna perencanaan SDM adalah proses untuk menetapkan strategi, memperoleh, memanfaatkan, mengembangkan dan mempertahankan tenaga kerja sesuai dengan kebutuhan sekarang dan pengembangannya di masa mendatang.

Perencanaan merupakan sunatullah. Karena sesungguhnya Allah menciptakan alam semesta ini dengan hak dan perencanaan

52Veithzal Rivai, Islamic Human Capital dari teori ke Praktik, (Jakarta: PT. Rajagrafindo, 2009), hlm. 51 Press, 2004)

53 Husaini Usman, Manajemen Pendidikan, (Yogyakarta: UNY 
yang matang, sebagaimana firman allah SWT dalam surah Shaad [38] : 27 sebagai berikut : ${ }^{54}$

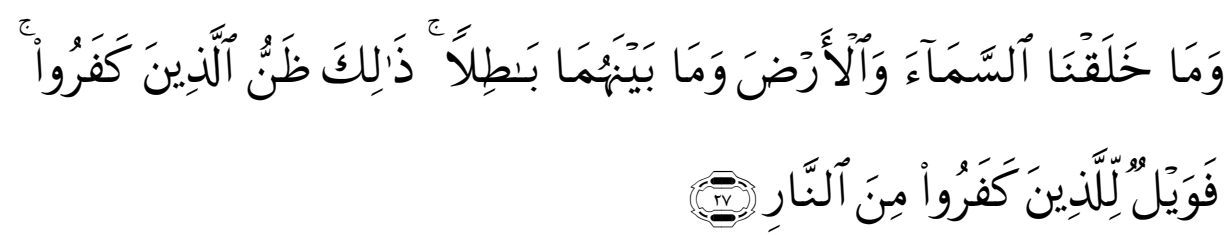

Artinya : dan Kami tidak menciptakan langit dan bumi dan apa yang ada antara keduanya tanpa hikmah. yang demikian itu adalah anggapan orang-orang kafir, Maka celakalah orang-orang kafir itu karena mereka akan masuk neraka.

Selanjutnya dalam surat Al-Zumar [39] :39 Allah Subhanahuata'ala berfirman :55

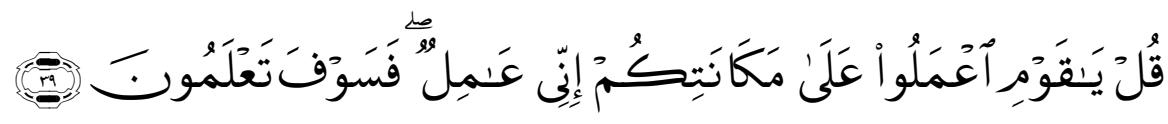

Artinya : Katakanlah: "Hai kaumku, Bekerjalah sesuai dengan keadaanmu, Sesungguhnya aku akan bekerja (pula), Maka kelak kamu akan mengetahui.

Dalam HR Ibnu Al-Mubarak, Rasululoh saw bersabda :"Jika engkau ingin mengerjakan sesuatu pekerjaan maka pikirkanlah akibatnya, maka jika perbuatan tersebut baik, ambillah dan jika perbuatan itu jelek, maka tinggalkanlah."

Perencanaan sangat penting dalam suatu organisasi, sudah selayaknya sebagai manusia membuat perencanaan dalam setiap aspek kehidupan. Berikut prinsip-prinsip perencanaan yang baik dalam pendidikan :

a. Menganalisa keadaan sekarang (tidak dimulai dari nol tetapi sumber daya yang sudah ada)

b. Keberhasilan dan faktor-faktor kritis keberhasilan

54 Departemen Agama RI, Op.Cit, hlm. 455

55 Ibid, hlm. 462 


\section{Desy Aniqotsunainy : Penerapan Fungsi Perencanaan SDM}

c. Kegagalan masa lampau

d. Potensi, tantangan, dan kendala yang ada

e. Kemampuan merubah kelemahan menjadi kekuatan, dan ancaman menjadi peluang.atau dengan kata lain, perencanaan yang baik harus dapat melaksanakan strategi yang dibuat berdasarkan SWOT (strengths, Weakness, Opportunities, and Threats).

Dalam konteks lembaga pendidikan, perencanaan mencakup dua hal yaitu : (1) Perencanaan Kepegawaian (employment planning), dan (2) Perencanaan Program (program planning). Perencanaan program menyangkut pemilihan alat SDM yang paling efektif yang terpusat pada kelebihan maupun kekurangan SDM. Perencanaan yang baik harus bersifat fleksibel, realistis dan perlu disertai program kerja (action plan) untuk menyusun kegiatan lembaga pendidikan, diperlukan data yang banyak dan valid, pertimbangan dan pemikiran oleh sejumlah orang yang berkaitan dengan hal yang direncanakan. Oleh karena itu kegiatan perencanaan sebaiknya melibatkan setiap unsur lembaga pendidikan tersebut dalam rangka peningkatan mutu pendidikan.

\section{Tujuan dan Posisi SDM}

1. Tujuan MSDM

Tujuan manajemen sumber daya manusia adalah merumuskan kebutuhan pegawai, mengembangkan dan memberdayakan pegawai untuk memperoleh nilai maslahat optimal bagi individu pegawai yang bersangkutan, organisasi dan masyarakat yang dilayaninya. 
2. Posisi SDM dalam Organisasi

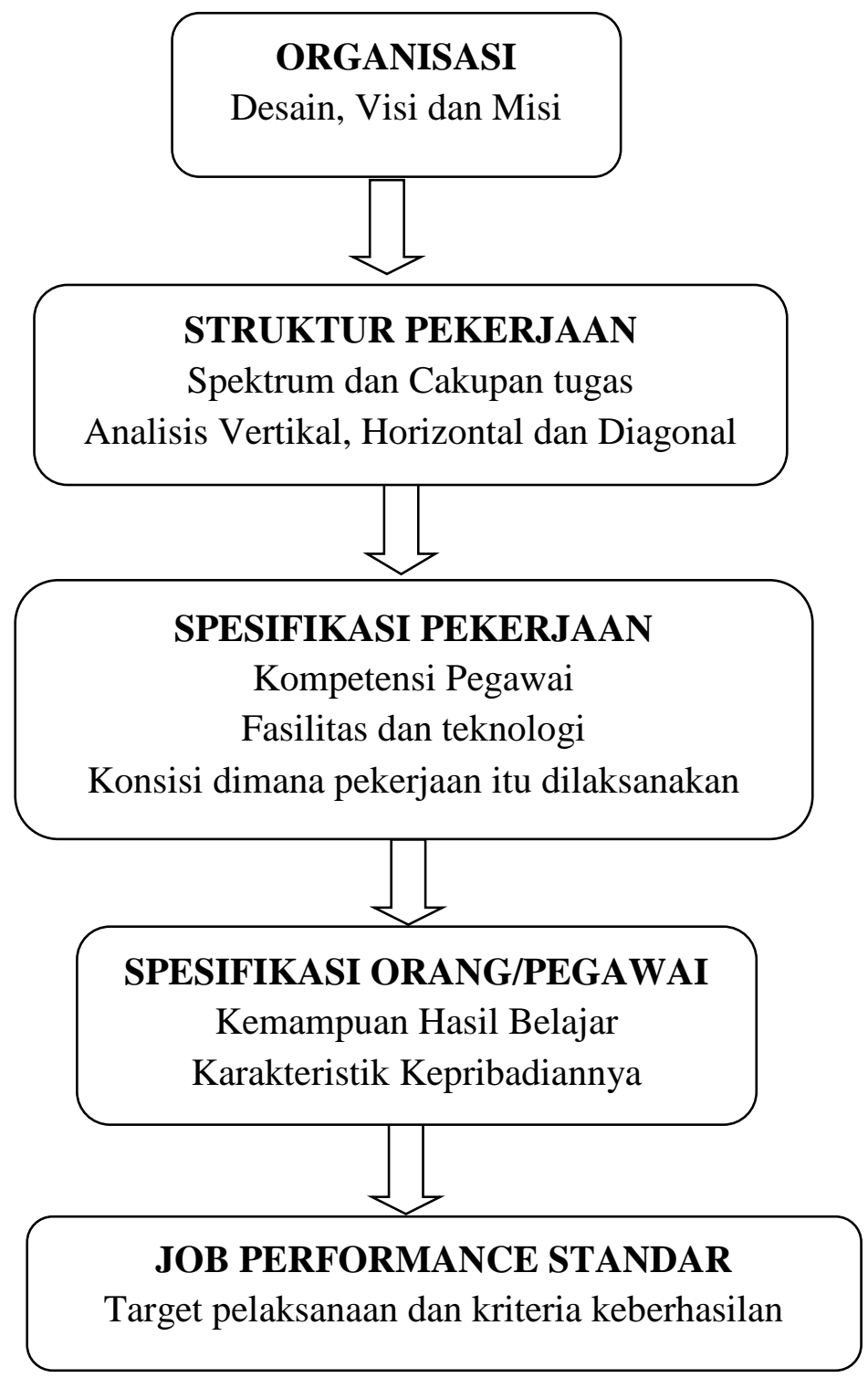

Gambar 2. Posisi SDM dalam Organisasi 


\section{Desy Aniqotsunainy : Penerapan Fungsi Perencanaan SDM}

Organisasi merupakan sekumpulan orang-orang yang saling bekerja sama untuk mencapai tujuan tertentu. Kemudian dijabarkan dalam bentuk visi,misi dan tujuan. Untuk mencapai hal tersebut maka perlunya di buat struktur pekerjaan yang meliputi analisis pekerjaan, deskripsi pekerjaan dan langkahlangkah analisis pekerjaan. Pengertian Analisis pekerjaan adalah prosedur untuk menentukan tanggung jawab dan persyaratan keterampilan yang dibutuhkan dari pekerjaan dan jenis orang yang harus dipekerjakan untuk pekerjaan tersebut.56Sedangkan Deskripsi pekerjaan adalah Daftar pekerjaan, tanggung jawab, hubungan pelaporan, kondisi pekerjaan, dan tanggung jawab pekerjaan. Dan Spesifikasi pekerjaan adalah daftar "persyaratan tenaga kerja" untuk pekerjaan, yaitu syarat pendidikan, keterampilan, kepribadian dan lainnya.

Langkah-langkah dalam analisis pekerjaan personal :

Tahap 1 : tentukan bagaimana anda mengumpulkan informasi tentang posisi pekerjaan

Tahap 2 : tinjaulah informasi dasar yang relevan, tentang bagaimana hubungan antara satu dengan yang lain, posisi pekerjaan dalam tata organisasi dll

Tahap 3 : memiih posisi yang dapat mewakili

Tahap 4 : menganalisis pekerjaan- dengan mengumpulkan aktivitas pekerjaan, perilaku karyawan yang dibutuhkan, kondisi pekerjaan, sifat dan kemampuan manusia dan lain-lain.

Tahap 5 : melakukan verifikasi informasi analisis pekerjaan

56 Gary Dessler. Manajemen Sumber Daya Manusia., terj. Benyamin Molan.(Jakarta: Prenhallindo, 2010). hlm 6 
Tahap 6 : membuat deskripsi pekerjaan dan spesifikasi pekerjaan

\section{Sasaran SDM}

Dasar Al-Qur'an mengenai sasaran-sasaran MSDM terdapat dalam QS Al-Hasyr (59) :18 yaitu : ${ }^{57}$

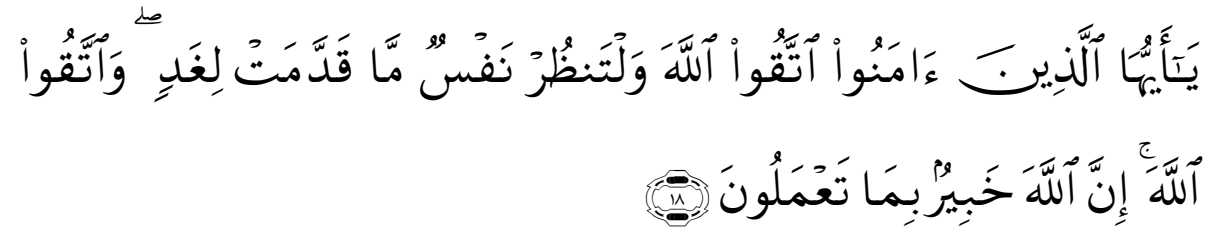

Artinya : Hai orang-orang yang beriman, bertakwalah kepada Allah dan hendaklah Setiap diri memperhatikan apa yang telah diperbuatnya untuk hari esok (akhirat); dan bertakwalah kepada Allah, Sesungguhnya Allah Maha mengetahui apa yang kamu kerjakan.

Sasaran yang di bahas dalam perencanaan SDM meliputi :

a. Sasaran perusahaan/instansi/sekolah.

untuk mengenali bahwa MSDM memberikan kontribusi atas efektivitas.

b. Sasaran fungsional

untuk mempertahankan kontribusi SDM pada level yang cocok bagi instansi/lembaga pendidikan

c. Sasaran social

untuk berdaya tanggap secara etis dan social terhadap kebutuhan dan tuntutan masyarakat

d. Sasaran pribadi karyawan

untuk membantu karyawan mencapai tujuan-tujuan pribadi mereka, sejauh dapat meningkatkan kontribusi individu atas perusahaan

57 Departemen Agama RI, Op.Cit, hlm. 548 


\section{Desy Aniqotsunainy : Penerapan Fungsi Perencanaan SDM}

\section{Penerapan perencanaan dengan menggunakan strategi SDM dalam Pendidikan}

Masalah yang dihadapi MSDM saat ini adalah cepatnya perubahan yang terjadi pada lingkungan pendidikan yang kompetitif berdampak pula pada perencanaan SDM yang dimiliki. Manajemen SDM merupakan bidang strategis sebagai perluasan dari pandangan tradisional untuk mengelola SDM secara efektif dan untuk itu membutuhkan pengetahuan tentang perilaku manusia dan kemampuan untuk mengelolanya. Proses strategi manajemen SDM di bawah ini:

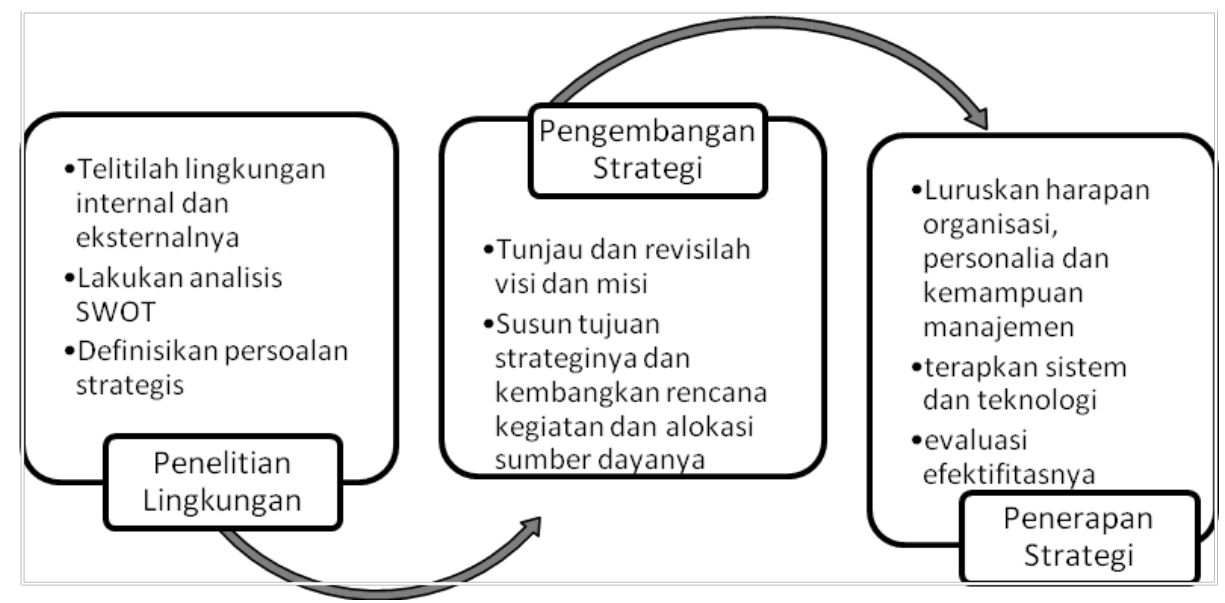

Gambar 3. Proses Strategi Manajemen

Beragam strategi manajemen SDM, di susun dan diterapkan dalam konteks sebagai perencanaan fungsional, seperti strategi pemasaran pendidikan, strategi finansial, strategi sistem akademik, strategi teknologi kesemuanya disusun dalam kerangka yang sama, yaitu strategi untuk memberikan suatu bimbingan yang lebih fleksibel dan beradaptasi pada suatu lembaga/organisasi. Berikut salah satu penerapan strategi mutu guru. 


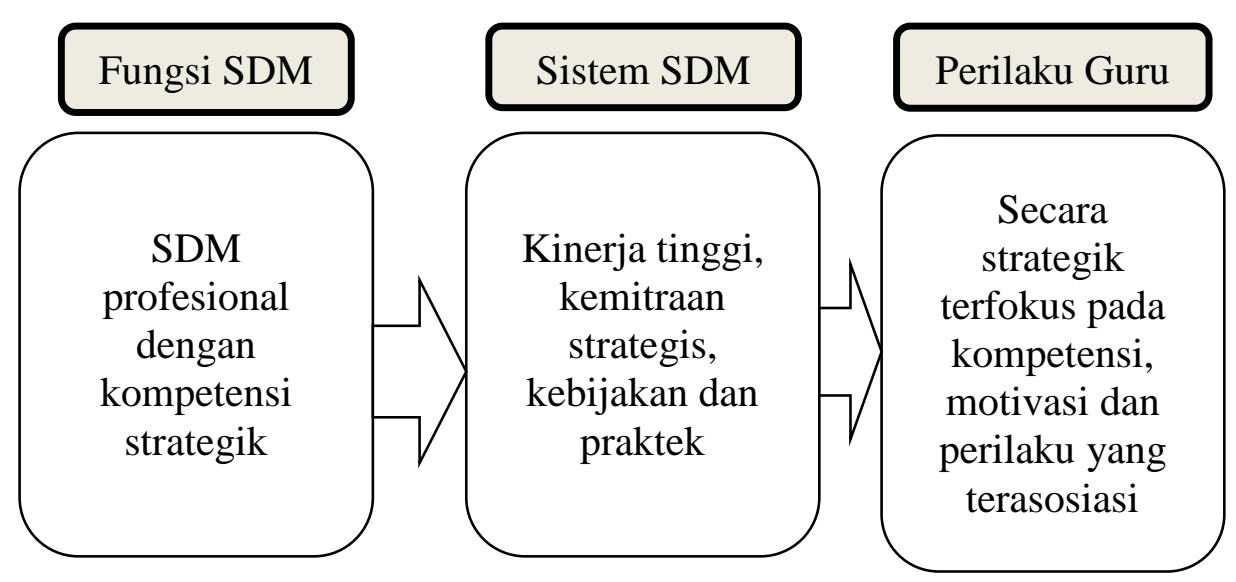

Penjelasan tentang gambar di atas sebagai berikut :

\section{a. Fungsi SDM}

Penerapan fungsi SDM dalam pendidikan dengan menerapkan manajemen SDM pendidikan yang efektif yang bisa dibedakan menjadi ada 2 (dua) dimensi :

1) Manajemen pendidikan secara teknis : mencakup rekrutmen guru, kompensasi yang diterima, dan benefit bagi guru dll.

2) Manajemen SDM pendidikan yang strategik : mencakup penyampaian pelayanan manajemen SDM pendidikan secara teknis dalam cara mendukung berlangsungnya strategi sekolah

b. Sistem SDM

Menerapkan model sistem HPWS "high performance work system" sebagai berikut :

1) Menghubungkan seleksi dan promosi guru untuk mevalidasi model kompetensi guru

2) Mengembangkan strategi yang menyediakan waktu dan dukungan efektif untuk keterampilan sesuai tuntutan 


\section{Desy Aniqotsunainy : Penerapan Fungsi Perencanaan SDM}

3) Melaksanakan kebijakan kompensasi dan pengelolaan kinerja guru yang menarik, mempertahankan dan memotivasi kinerja guru yang tinggi

c. Perilaku Guru

Secara strategik akan terbentuk perilaku guru yang terfokus pada kompetensi, motivasi dan perilaku yang terasosiasi. Menurut Edgar Schein yang dikutip David Wijaya, perencanaan suksesi karier merupakan suatu proses penemuan yang berkesinambungan atau proses dimana seseorang secara perlahan-lahan mengembangkan konsep diri tentang pekerjaan yang lebih jelas jika dilihat dari bakat, kemampuan, motif, kebutuhan, sikap, dan nilai-nilainya. 58 Berikut contoh penerapan perencanaan sukses guru.

1) Mengidentifikasi langkah karir guru

Identifikasi tentang karir guru, bakat dan keterbatasan guru, nilai-nilai yang dimiliki guru

2) Mengidentifikasi orientasi pekerjaan guru

John holland, 6 tipe kepribadian dasar guru : realistik, penyelidikan, sosial, konvensional, kewiraswastaan, dan artistik.

3) Mengidentifikasi keterampilan guru, motivasi, keterampilan kedudukan, kecerdasan (kemampuan bawaan, intelegensi, artistik, mekanik dll)

4) Mengidentifikasi jangkar karir guru (poros yang disekelilingnya karir guru akan berputar). Karir fungsional, karir kompetensi manajerial, karir kreativitas d11)

58 David Wijaya, Manajemen Sumber daya Manusia Pendidikan Berbasis Kompetensi Guru Dalam rangka Membangun Keunggulan Bersaing sekolah, http://jurnal.pdii.lipi.go.id, diakses tanggal 16 November 2015 


\section{E. Penutup}

Memilih profesi guru merupakan profesi yang sangat menguntungkan, baik di masyarakat yang memandang terhormat ilmunya, bahkan Islam menempatkan guru sebagai orang yang paling beruntung di akhirat. Guru juga harus peka dan tanggap terhadap perubahan, pembaharuan serta ilmu pengetahuan dan teknologi yang terus berkembang sejalan dengan tuntutan perkembangan zaman. Disinilah peran pelaku/pemimpin pendidikan dalam merumuskan perencanaan strategi sumber daya manusia untuk memilih kualitas guru yang ideal, yang tampil sebagai pendidik, pengajar, inovator maupun dinamisator baik untuk masa kini maupun masa mendatang guna mencapai tujuan mencerdaskan bangsa. 


\section{DAFTAR PUSTAKA}

Departemen Agama RI, Al-Qur'an Tajwid dan Terjemah, (Bandung: CV Penerbit Diponegoro,2010)

David Wijaya, Manajemen Sumber daya Manusia Pendidikan Berbasis Kompetensi Guru Dalam rangka Membangun Keunggulan Bersaing sekolah, http://jurnal.pdii.lipi.go.id, diakses tanggal 16 November 2015

E. Mulyasa, Menjadi Guru Profesional Menciptakan Pembelajaran Kreatif dan Menyenangkan (Bandung: Remaja Rosdakarya, 2007)

Gary Dessler. Manajemen Sumber Daya Manusia., terj. Benyamin Molan.(Jakarta: Prenhallindo, 2010)

Husaini Usman. Manajemen Pendidikan. (Yogyakarta :UNY Press, 2004)

Isjoni, Guru Sebagai Motivator Perubahan, (Yogyakarta: Pustaka Pelajar, 2009)

Veithzal Rivai, Islamic Human Capital dari teori ke Praktik, (Jakarta: PT. Rajagrafindo, 2009) 